\title{
Cooperación tributaria \\ internacional y movilidad del capital
}

\section{Valpy FitzGerald \\ Universidad de Oxford edmond.fitzgerald \\ @ st-antonys.oxford.ac.uk}

La movilidad internacional del capital y la dispersión geográfica de las empresas ofrecen evidentes ventajas para el crecimiento y la modernización de América Latina y el Caribe, pero también plantean enormes desafíos tributarios. Según los principios modernos de tributación del capital para economías abiertas en desarrollo, debe equilibrarse el fomento de la inversión privada y la financiación de la infraestructura social, ambos necesarios para el crecimiento sostenible. Tal equilibrio puede resultar subóptimo cuando los países compiten por la inversión extranjera, otorgando incentivos tributarios, o aplican principios contradictorios al determinar la base tributaria. Las autoridades fiscales de la región podrían obtener una proporción más equitativa de las recaudaciones por impuestos de capital, sin reducir la inversión ni el crecimiento, mediante normas tributarias más eficaces, tratados de doble tributación, intercambio de información y tratamiento de los centros financieros extraterritoriales según los lineamientos promovidos para los miembros de la OCDE. 


\section{I}

\section{Introducción}

La globalización conlleva una mayor libertad de movimiento de los capitales, tanto para las empresas de los países industrializados que invierten en los países en desarrollo como para los poseedores de activos financieros de estos últimos. Según los principios vigentes de tributación internacional, los factores de producción menos móviles son los que deberían soportar la mayor parte de la carga tributaria, a fin de aprovechar al máximo los ingresos fiscales y reducir al mínimo los elementos que desincentivan el crecimiento económico. En la medida en que los gobiernos han tratado de mantener los niveles de ingresos fiscales e inversión privada, se ha registrado un desplazamiento concomitante de la incidencia de la tributación desde el capital a la mano de obra. En las principales economías latinoamericanas, la carga tributaria estimada sobre los ingresos de los inversionistas extranjeros ha bajado casi a la mitad en las dos últimas décadas.

Así pues, el libre movimiento de los capitales y las oportunidades para la dispersión geográfica de las empresas plantean enormes desafíos a las autoridades tributarias. Las diferentes normas nacionales de tributación y los intersticios entre las administraciones tributarias crean conflictos de intereses entre todos los involucrados. Por un lado, la doble tributación internacional que comporta el ejercicio simultáneo de dos países o más de sus derechos de tributación no propicia la realización de acuerdos comerciales en general ni de inversiones en particular. Por otro, la falta de coordinación administrativa entre jurisdicciones tributarias favorece la fuga de capitales y la pérdida de cuantiosos ingresos fiscales. Por consiguiente, en los últimos años los gobiernos miembros de la Organización de Cooperación y Desarrollo Económicos (OCDE) han reforzado las medidas destinadas a evitar "la dañina competencia tributaria". No obstante, el problema aqueja tanto a los países en desarrollo como a los

$\square$ Este artículo se basa en un texto preparado para servir de apoyo al documento de la CEPAL titulado Globalización y Desarrollo, que se presentó en el $29^{\circ}$ período de sesiones de la Comisión (Brasilia, 6 al 10 de mayo de 2002). Quisiera agradecer a Rodrigo Cubero y a Alex Cobham por su asistencia en el área de investigación. desarrollados. América Latina y el Caribe han estado a la vanguardia de la liberalización de los movimientos de capital, pero también se han visto afectados por los trastornos crónicos que provocan los déficit fiscales, la deuda externa y la deficiente infraestructura.

Los actuales sistemas internacionales de tributación plantean problemas especiales, vinculados a: i) las dificultades para adquirir los posibles recursos fiscales generados por las empresas transfronterizas extranjeras y nacionales; ii) los costos económicos de la competencia tributaria entre países en desarrollo tendiente a atraer inversión extranjera, y iii) las consecuencias en términos de fuga de capitales y equidad social de la incapacidad de gravar los activos en el extranjero de los residentes. Pese a tales problemas, los pagos de impuestos de los inversionistas extranjeros constituyen una fuente importante de recursos fiscales para la región: en el año 2000 las empresas foráneas habrían pagado unos 15000 millones de dólares en impuestos sobre los ingresos, en tanto que los impuestos pagaderos sobre los ingresos procedentes de las tenencias en cartera de los residentes en el exterior también podrían alcanzar similar magnitud. En todo caso, los sistemas de tributación internacional deberían considerarse vitales para la política de desarrollo internacional, tal como lo han pasado a ser la inversión y las normas comerciales.

En la sección II se bosqueja el marco institucional para la cooperación tributaria internacional: competencia tributaria, principios contradictorios para determinar la base tributaria y tratados de doble tributación. En la sección III se abordan los principios económicos que fundamentan los debates de política sobre el dilema de una economía abierta que necesita alentar la inversión privada y financiar la infraestructura social. En la sección IV se examina la tributación internacional en su aplicación práctica, considerando tanto la evidencia estadística sobre los flujos de capital como el avance actual en el intercambio de información y la supervisión de los centros financieros extraterritoriales. El trabajo concluye con el análisis de una posible agenda para el debate de política regional, que figura en la sección V. 


\section{II}

\section{El marco institucional para la cooperación tributaria internacional}

La movilidad del capital ha transformado la política tributaria nacional. Los actuales sistemas tributarios fueron diseñados, tras la segunda guerra mundial, en un entorno de protección comercial e inmovilidad del capital y la mano de obra. En ese entorno era factible aplicar tasas muy diferentes de impuestos directos e indirectos. Sin embargo, esa situación ya no es válida hoy (Tanzi, 1996a y 1998). Es más, se suele sostener que en una economía cerrada los impuestos sobre los ingresos de las empresas son ineficientes porque alientan la excesiva reinversión de las utilidades, y que basta con cobrar impuestos sobre el ingreso personal a los perceptores de dividendos (y ganancias del capital). Además, si se desea incentivar el ahorro, se suele sugerir que sólo se debe gravar el consumo. Sea cual fuere su validez conceptual, en la práctica estos argumentos no se aplican directamente a los países en desarrollo o industrializados pequeños (OCDE, 2001). Por un lado, en ellos se observa un grave problema de distribución del ingreso, que exige una redistribución de la riqueza (y por ende de los impuestos sobre el capital) a fin de reducir la pobreza y aumentar la cohesión social. Por otro, gran parte de sus activos más productivos pertenece a no residentes, mientras que gran parte de la riqueza de los residentes se encuentra en el exterior. Por lo tanto, la tributación de los ingresos del capital es un asunto cuya importancia para la política de desarrollo no puede soslayarse.

Sin embargo, a falta de un gobierno mundial único, un tema clave de la tributación internacional es el nivel apropiado del impuesto nacional sobre los ingresos de las empresas ante la integración a los mercados de capital internacionales. En general, quienes formulan las políticas consideran esencial bajar las tasas, a fin de atraer la inversión extranjera y así aumentar el ritmo de crecimiento económico. El peso del factor tributario en las decisiones sobre localización produce una antieconómica competencia por la inversión (OCDE, 1998) y, por ende, una "carrera hacia el abismo", ya que los países en desarrollo compiten con otros países receptores y también con decrecientes impuestos sobre los ingresos de las empresas en sus países de origen (UNCTAD, 1995).
La mayoría de los países de América Latina y el Caribe - así como otras economías en desarrollointentan atraer inversión extranjera con políticas de incentivos tributarios, ya sea para compensar las distorsiones e ineficiencias locales, o simplemente para evitar que la inversión extranjera se dirija a países vecinos o semejantes. No obstante, la evidencia empírica indica que tales incentivos desempeñan un papel muy limitado como determinantes de la inversión extranjera, y que incluso cuando tienen éxito entrañan significativos costos fiscales. ${ }^{1}$ Para las empresas inversionistas, la reducción de la incertidumbre regulatoria es tan importante como las concesiones o incentivos que pueda contener un tratado. Aparentemente las empresas transnacionales consideran que los incentivos tributarios son una ventaja inesperada y no la base para tomar decisiones de inversión de largo plazo, ya que posteriormente pueden ser modificados. Esto no impide que los inversionistas negocien para conseguir tales concesiones, pero ellas sólo influyen, cuando más, en las decisiones de localización dentro de un país, a igualdad de los demás factores de costo.

En el diseño de los regímenes impositivos sobre los activos de los no residentes y los activos de los residentes en el extranjero se utilizan dos modelos, que son similares en sus disposiciones generales pero tienen muy diferentes consecuencias para los países en desarrollo. El proyecto de Convención sobre la tributación/Convenciones modelo sobre la tributación (OCDE, 1997) se basa en el criterio de tributación según la residencia, en tanto que la Convención modelo de las Naciones Unidas sobre la doble tributación entre países desarrollados y países en desarrollo (Naciones Unidas, Departamento de Asuntos Económicos y Sociales, 2001) se basa en el criterio de tributación según la fuente (o "territorial"). Los países en desarrollo saldrían más beneficiados con un tratado multilateral basado en el principio de tributación según la fuente, por dos razones. Primero, porque las

\footnotetext{
${ }^{1}$ Véanse Plasschaert (ed., 1994) y Blomström (2001), y más adelante, la sección IV.
} 
ganancias procedentes de gravar los ingresos de los inversionistas extranjeros serían mayores que la pérdida derivada de no gravar los ingresos por activos en el exterior de sus propios residentes, debido a que los países en desarrollo tienen una posición neta de pasivos externos. Segundo, incluso si las autoridades del país de destino aplicaran plena tributación sobre estos activos externos de los residentes de países en desarrollo sobre la base del principio de tributación según la fuente, ello haría al menos que la fuga de capitales fuera mucho menos atractiva.

El principio de tributación según la fuente también suele adoptarse porque las administraciones tributarias tienen grandes dificultades para determinar la magnitud de los ingresos extranjeros que obtienen sus residentes. El principio de tributación según la residencia, aunque se basa en la capacidad de pago global, ha resultado de utilidad limitada en países cuyos residentes no tienen inversiones sustanciales (registradas) en otros países, y cuya administración fiscal no está bien dotada para velar por su aplicación. Además, en la medida en que los países desarrollados aplican simultáneamente los principios de tributación según la fuente y según la residencia a sus propios residentes, retienen impuestos de sus propios inversionistas en los países en desarrollo, en tanto que si no gravan las tenencias en papeles de los no residentes, estimulan la fuga de capitales desde los países en desarrollo. Por ejemplo, en los Estados Unidos se gravan tanto los ingresos externos de los residentes estadounidenses como los ingresos obtenidos en los Estados Unidos por los no residentes. ${ }^{2}$ Además, normalmente el país no reconoce en su totalidad los impuestos pagados en el extranjero como parte de las obligaciones tributarias en los Estados Unidos.

Los países en desarrollo tienen un problema adicional: cómo equilibrar la maximización de su parte de los ingresos con la mantención de un entorno que resulte atractivo para la inversión extranjera directa (IED). Para enfrentarlo es preciso contar con acuerdos para compartir los ingresos entre el país receptor y el país de origen, en lo que es casi un juego de suma cero, que en última instancia implica una transferencia neta entre los contribuyentes de ambos países. Al firmar un tratado tributario, el país receptor también suscribe

\footnotetext{
${ }^{2}$ Véase un resumen de las normas vigentes en los Estados Unidos sobre tributación internacional en Congreso de los Estados Unidos, JCT (1999).
}

normas internacionales que promueven la estabilidad, la transparencia y la seguridad del trato.

Como los sistemas tributarios de los principales países de origen (por ejemplo, de la OCDE) están basados en principios internacionales de tributación sobre los ingresos, sus empresas transnacionales suelen estar sujetas a cierto grado de doble tributación. Esto no sólo refrena la inversión internacional, sino que también alienta el uso de paraísos fiscales para canalizar corrientes de capitales transfronterizos mediante la incorporación de holdings extraterritoriales. El uso de estos mecanismos va en detrimento del país receptor y del país de origen, dado que se reduce la recaudación de impuestos y se distorsionan los flujos de inversión.

El número de acuerdos de doble tributación, por lo tanto, ha aumentado rápidamente en las últimas décadas: actualmente existen unos dos mil (cuadro 1). El principio de no discriminación (es decir, de trato nacional) ha formado parte integrante de tales tratados desde el siglo pasado, y fue fundamental para el proyecto de Convención preparado por la Liga de Naciones en 1935 (IBFD, 1998). Los acuerdos de doble tributación originalmente se establecieron entre países desarrollados pero, con la expansión reciente, han llegado a abarcar también a los países en desarrollo: $34 \%$ del total corresponde a acuerdos entre países desarrollados y en desarrollo, y otro $17 \%$ a acuerdos entre países en desarrollo. Evidentemente, siguen el mismo camino que los tratados bilaterales sobre inversiones, que establecen las correspondientes disciplinas de protección del inversionista.

El efecto de los tratados sobre tributación depende de los créditos y las exenciones que contienen a fin de eliminar o reducir la doble tributación. Cuando los países tienen un nivel semejante de desarrollo - y las inversiones en ambos sentidos son más o menos equilibradas-, la redistribución implícita no plantea un problema serio, pero para los países receptores (en desarrollo) los ingresos marginales tienen mayor valor que para los países de origen (desarrollados). Dado que los flujos de ingresos generalmente van de los

CUADRO 1

Mundo: Acuerdos de doble tributación y tratados bilaterales sobre inversiones

\begin{tabular}{lrrr}
\hline & 1980 & 1990 & 2000 \\
\hline Acuerdos de doble tributación & 700 & 1150 & 2118 \\
Tratados bilaterales sobre inversiones & 200 & 400 & 1941 \\
\hline
\end{tabular}

Fuente: UNCTAD (2001). 
países en desarrollo a los países desarrollados, el método de créditos fiscales es el más atractivo para los primeros. Desde el punto de vista de sus autoridades fiscales, los acuerdos de doble tributación constituyen la única manera de cubrir transacciones intrafirma y así superar el problema de la determinación de los precios de transferencia (OCDE, 1997).

Estos acuerdos, sin embargo, pierden eficacia si se utilizan centros extraterritoriales como puntos de fijación de precios de transferencia así como de elusión fiscal. Además, hay una serie de países en desarrollo que tienen un papel extraterritorial clave en el proceso de inversión internacional, en que la elusión fiscal reviste particular importancia. En este caso no se trata tanto de atraer inversión extranjera como tal, sino más bien de administrar activos e ingresos fiscales. ${ }^{3} \mathrm{En}$ consecuencia, a falta de un acuerdo tributario multilate- ral amplio, sería conveniente reconsiderar los créditos fiscales dentro de los acuerdos de doble tributación existentes, así como la aplicación del principio de los Estados Unidos de "traslado" a los paraísos fiscales.

Por último, no hay que olvidar que para los países en desarrollo la recaudación de los impuestos sobre el ingreso de sus propios residentes que tienen activos en el extranjero también es un problema de envergadura. Por consiguiente, una colaboración internacional más estrecha aun dentro de la red de acuerdos de doble tributación existentes, mediante el intercambio de información y el fomento de medidas conjuntas, podría aumentar enormemente los recursos fiscales de que disponen los países en desarrollo (OCDE, 1998, y Tanzi, 1996a). Entre otros beneficios, también se incluiría la desincentivación de la fuga de capitales y la mayor estabilidad de la balanza de pagos.

\section{III}

\section{Los principios económicos de la tributación sobre los ingresos de capital y la coordinación impositiva}

Según la perspectiva tradicional de la tributación sobre los ingresos de capital en las economías abiertas, ${ }^{4}$ la tributación según el principio de la residencia reduce la rentabilidad después de impuestos del ahorro interno, al marcar una discrepancia entre la tasa de retorno de los mercados financieros mundiales y la rentabilidad después de impuestos recibida por los residentes -en otras palabras, habría un impuesto sobre la propiedad del capital o "ahorro"impuestos según la fuente elevan la rentabilidad requerida de la inversión interna por encima de la tasa de los mercados financieros mundiales y, por ende, equivalen a impuestos sobre la ubicación del capital, es decir, sobre la inversión. En consecuencia, la literatura tradicional recomienda que una pequeña economía

\footnotetext{
${ }^{3}$ Se observa así un proceso que, en ocasiones, se ha descrito como "degradación fiscal", según el cual algunos países pueden cambiar sus sistemas impositivos a fin de "saquear" la base tributaria mundial y exportar su carga impositiva (Tanzi, 1996b, p. 3).

${ }^{4}$ Por ejemplo, véase Gordon (1986), Giovannini (1990) o Stern y Newbery (eds., 1985).
}

abierta no debe aplicar en caso alguno la tributación sobre los ingresos de capital según la fuente, sino que debe adoptar sólo sistemas basados en la residencia.

La aplicación universal del principio de la residencia nivelaría la rentabilidad bruta del capital, de manera que asignaría con eficiencia el capital mundial (pero no el ahorro); en tanto, la aplicación universal del principio de la fuente asignaría eficientemente el ahorro mundial (pero no el capital), al nivelar las tasas marginales intertemporales de sustitución. Así pues, según la teoría de la tributación óptima, aun en un mundo subóptimo (donde no puede alcanzarse la eficiencia de Pareto debido a la necesidad de aumentar los impuestos para financiar los bienes públicos y con propósitos redistributivos), el principio de la residencia es preferible debido a que al menos asegura la eficiencia productiva (Diamond y Mirrlees, 1971).

También se estima preferible la tributación según la residencia porque permite aplicar tasas progresivas por razones de equidad. Sin embargo, si los impuestos de esta índole no pueden recaudarse eficazmente (debido a la falta de información fiscal, capacidad 
administrativa o cooperación internacional), los impuestos sobre los ingresos de capital en su conjunto pasan a no ser convenientes. En suma, el resultado tradicional a partir de la literatura sobre la tributación óptima es que las pequeñas economías abiertas no deberían adoptar sistemas tributarios basados en la fuente y deberían eliminar totalmente los impuestos sobre los ingresos de capital si los países no pueden aplicar impuestos basados en el criterio de la residencia (Bovenberg, 1994, p. 118).

Este resultado se basa en cuatro supuestos: i) que el capital es perfectamente móvil; ii) que el gobierno puede gravar libremente los factores de producción inmóviles, en particular la mano de obra; iii) que no hay compensación tributaria en el país de origen por impuestos de capital pagados en el país receptor, y iv) que el gobierno puede gravar de manera eficaz los ingresos de los activos que los residentes tienen en el exterior. En consecuencia, se argumenta que la tributación según la fuente se traslada completamente a factores inmóviles (incluida la mano de obra), ya que, debido a la perfecta movilidad internacional del capital, la oferta de éste es infinitamente elástica, de manera que un impuesto explícito sobre la mano de obra es más eficaz.

Los países más pobres se han visto más presionados que los países más ricos para que reduzcan las tasas de tributación que se aplican a filiales de empresas transnacionales extranjeras. Esto implica que -al menos para los fines de la inversión extranjera directa - la competencia tributaria afecta en mayor grado y de manera desproporcionada a los países más pobres. Según Haufler y Wooton (1999), la competencia tributaria —incluso entre países industrializados- para atraer la inversión extranjera directa puede llevar a que las empresas transnacionales expropien los ingresos por concepto de dotación de recursos y ubicación, lo que justifica las medidas adoptadas por la Organización de Cooperación y Desarrollo Económicos (OCDE) y la Unión Europea para evitar esa competencia dañina entre sus respectivos miembros. Lo mismo se aplica, con mayor razón, a los países en desarrollo.

Sin embargo, los supuestos enumerados no rigen en la práctica. El capital no es perfectamente móvil en el ámbito internacional, ya que se ve atraído por determinadas economías en desarrollo debido al tamaño de su mercado y a su dotación de recursos o capital humano; de manera que los inversionistas, ya sean extranjeros o nacionales, no se libran totalmente de los impuestos sobre los ingresos de capital. Los gobiernos no pueden gravar libremente los factores inmóviles (como la mano de obra) por razones de equidad y además porque, según el modelo tradicional, se supone que la oferta de mano de obra es exógena. Si los niveles salariales afectan la oferta o la productividad de la mano de obra, entonces existe una relación inversa (trade-off) con las distorsiones del mercado de capital, como lo demuestran Sen y Turnovsky (1990).

Como hemos visto, los sistemas internacionales de créditos fiscales sí existen y, en efecto, los tratados de doble tributación están diseñados para ofrecer una transferencia directa entre autoridades fiscales y así no afectar las decisiones de inversión (Frenkel, Rain y Sadka, 1991). En consecuencia, los países recurren de hecho a impuestos sobre los ingresos de capital basados en el criterio de la fuente, lo que explica por qué los resultados obtenidos de la teoría de tributación óptima no se han dado en la práctica (Slemrod, 1990). Por último, es evidente que hay considerable capacidad para mejorar la coordinación entre las autoridades fiscales y financieras de todo el mundo.

Además, dentro de un riguroso modelo dinámico diseñado para incluir estos efectos macroeconómicos, Bovenberg (1994) revela que los gobiernos pueden neutralizar el efecto que tienen los impuestos según la fuente sobre el comportamiento de los inversionistas si permiten que las empresas amorticen sus nuevos gastos de inversión con cargo a las obligaciones tributarias vinculadas a los ingresos de capital, con lo cual el gravamen se convierte en un impuesto sobre el flujo monetario solamente. El impacto intergeneracional de la tributación según la residencia también puede neutralizarse con una deducción impositiva por ahorro nuevo. Además, el impacto intergeneracional de ambas formas de impuesto puede contrarrestarse con una política apropiada en materia de deuda pública.

Los impuestos sobre los ingresos de capital también discriminan entre diferentes formas de financiación (por ejemplo, de cartera versus inversión directa), de manera que pueden utilizarse diferentes combinaciones de impuestos sobre dividendos, ingresos por concepto de intereses o ganancias de capital, además de impuestos sobre las empresas (impuestos basados en la fuente que se aplican a los ingresos del capital social) para alcanzar el equilibrio deseado (Nielsen y Sorensen, 1991). Este enfoque supone que el acervo de capital es de propiedad nacional. Si es de propiedad extranjera, la carga de un impuesto según la fuente corre por cuenta de extranjeros (que obviamente no se verán afectados por un impuesto según la residencia), pero el impacto sobre la movilidad del capital 
depende tanto del costo de ajuste como de cualquier incentivo tributario compensatorio que ofrezca la economía de origen (Sorensen, 1990).

No obstante, el arbitraje tributario internacional impone graves restricciones a la capacidad de una determinada autoridad fiscal de establecer tasas impositivas sobre los ingresos de capital (y los productos básicos). La competencia tributaria internacional tiene lugar entre los países, explícita o implícitamente, cuando el capital puede moverse libremente entre ellos. Cuando los mercados de capital se equilibran, aunque cualesquiera dos países no coordinen explícitamente sus sistemas tributarios, cada uno debe de igual manera tomar en cuenta el sistema tributario del otro al diseñar el suyo propio. Como demuestran Razin y Sadka (1994), cuando ambos países adoptan uno de los principios polares (el criterio de la fuente o el de la residencia), los mercados internacionales de capital llegarán a un equilibrio a tasas de impuesto y de interés positivas; pero si adoptan principios diferentes (o una combinación de ellos), es posible que no haya un equilibrio viable. Sin embargo, si los mercados de capital están integrados pero los sistemas tributarios no están armonizados, surgirá la competencia tributaria.

Si ninguno de los dos países influye en los precios (es decir, son "pequeños" en relación con la economía mundial), esta competencia llevará a una nivelación de la productividad marginal de la inversión en los países (es decir, el principio de residencia). No podrá obtenerse más ganancia de la armonización tributaria y no es necesaria la coordinación intergubernamental. No obstante, algunos países (como los Estados Unidos) o grupos de países (como la Unión Europea) de hecho son "grandes" en el sentido de que pueden formular sus políticas fiscales en función de sus efectos en los precios mundiales. El país con algún poder monopólico de hecho provocará que la tasa de interés mundial se eleve por encima de su propio producto marginal de capital, si se trata de un inversionista extranjero neto. En este caso, la coordinación fiscal internacional será una mejora hacia el óptimo de Pareto (Dixit, 1985). Sin embargo, la existencia de un arreglo regional (como la Unión Europea) posibilita beneficios en virtud de la coordinación dentro de la región, lo que produce una mayor recaudación y mayor inversión interna, aun sin una coordinación mundial (Haufler y Wooton, 2001). Este último caso parecería ser pertinente para países de regiones en desarrollo como América Latina o el Caribe.

Aun así, también es evidente (y se refleja en las teorías de crecimiento endógeno modernas) que la provisión de "infraestructura" —en forma no sólo de caminos sino asimismo de educación, salud, investigación y hasta legislación - también es esencial para el crecimiento. Tal infraestructura debe financiarse con alguna forma de tributación, pero existen límites sociales a la recaudación posible a partir de los ingresos de la mano de obra en sociedades con bajos niveles de ingreso per cápita. Así pues, surge una compensación potencial entre las bajas tasas impositivas sobre las empresas para estimular la inversión privada (interna y externa), por un lado, y las altas tasas destinadas a financiar la provisión de infraestructura física y social, por el otro. No queda claro, por lo tanto, si las tasas impositivas más bajas son necesariamente las más propicias para el crecimiento.

La "nueva geografía económica" ofrece buenas razones analíticas para creer que el capital no es enteramente móvil (es decir, indiferente a la ubicación) debido a las economías de concentración, etc., de modo que el potencial de recaudación tributaria también resulta afectado. Más que tomar parte en una simple "carrera hacia el abismo", las economías centrales avanzadas tal vez puedan actuar como semimonopolios al fijar "precios" (o sea, impuestos) en contra de las economías periféricas menos avanzadas. Sin embargo, quizá la integración no lleve a reducir las tasas impositivas y pueda ser coherente con el mantenimiento de grandes Estados de bienestar (Baldwin y Krugman, 2000). Por su parte, Kind, Knarvik y Schjelderup (1999) extienden formalmente este resultado, ya que encuentran que es necesario gravar el capital con un impuesto según la fuente para captar la externalidad positiva que surge de la concentración. Debido a la existencia de costos de transacción y economías de escala, los inversionistas se sienten atraídos por los mercados más grandes, que luego precisan menos incentivos tributarios para atraer inversiones que si no fuera así (Haufler y Wooton, 1999). Por último, estos impuestos sobre el capital semimóvil pueden usarse para producir un bien público y aliviar la presión tributaria sobre los trabajadores inmóviles (Andersson y Forslid, 1999).

Los aspectos analíticos de este problema se presentan en el apéndice, en el marco de un modelo simple de una economía con un mercado de capital abierto y dos tipos de capital. Si existe sólo un tipo de capital —móvil y privado-, entonces el modelo reproduce el resultado convencional de que todo incremento de la tasa impositiva de las empresas nacionales reducirá el ingreso nacional. La tasa tributaria óptima es cero, o incluso negativa (subsidios) si éstos pueden financiarse con cargo a impuestos sobre otro factor inmóvil, como la mano de obra. Además, está claro que 
si se reduce la tasa impositiva de las empresas internacionales o la de quienes compiten por la inversión interna extranjera, luego, a fin de mantener los niveles de ingreso nacional, será necesario reducir también la tasa impositiva de las empresas nacionales. Sin embargo, una vez que se introduce un segundo tipo de capital —infraestructura social—, resulta óptima una tasa tributaria positiva sobre las empresas, ya que aunque reduce el acervo de capital privado, como antes, también aumenta el acervo de capital público. El valor óptimo de la tasa impositiva depende de la productividad marginal de ambas formas de capital.

Las implicaciones de política son considerables. Por un lado, en los países en desarrollo con una infraestructura relativamente escasa y cuya productividad marginal es mayor (en tanto que la productividad marginal del capital móvil se iguala a escala mundial), hay argumentos económicos sólidos para que las tasas impositivas de las empresas sean mayores que en los países avanzados. De hecho, los países receptores deberían fijar su tasa tributaria óptima independientemente de la tasa internacional. Por otra parte, también es cierto que el nivel de ingreso nacional resultante depende en efecto de la tasa impositiva internacional, y cuando los países de origen -o los países receptores competidores - la reducen, el ingreso nacional baja. No obstante, y de mayor relevancia aún, el modelo indica que incluso en estas circunstancias, la presión por mantener baja la tasa impositiva de las empresas reducirá aún más el ingreso nacional.

En suma, hay sólidas razones, bien fundamentadas en la teoría económica, para creer que con una tributación más eficaz de los ingresos procedentes de los activos extranjeros se puede obtener cuantiosos recursos fiscales para apoyar el desarrollo sostenible de América Latina y el Caribe. Para los países en desarrollo que tienen obligaciones externas mayores que sus activos en el exterior, y que tienen considerables dificultades para registrar estos últimos, los impuestos sobre los ingresos de capital según la fuente son la mejor solución. Sus efectos distorsionadores sobre la inversión pueden mitigarse con un buen plan tributario (particularmente compensaciones por reinversión nacional y créditos fiscales internacionales).

\section{IV}

\section{Problemas prácticos de la tributación internacional}

En la práctica, la tributación de los activos internacionales tiene que ver con el carácter de residente o no residente del titular, por un lado, y con las filiales de empresas y los activos de cartera por el otro. El principal interés radica, de hecho, en la tributación de las filiales de empresas extranjeras, es decir, los flujos de IED desde el exterior. En América Latina y el Caribe, el acervo de ese tipo de IED hasta 2000 ascendía a 607000 millones de dólares (UNCTAD, 2001). Suponiendo que los pagos registrados de impuestos sobre los ingresos que efectúan las filiales de las empresas estadounidenses (como se verá más adelante) son representativos de todas las inversiones extranjeras en la región, el monto total de los ingresos tributarios de esta categoría pagados a los países receptores fue de aproximadamente 15000 millones de dólares en 2000. En ese año, el acervo de IED de los países de América Latina y el Caribe en el exterior (es decir, de filiales en el exterior) se evaluó en 111000 millones de dólares (UNCTAD, 2001), pero no existen registros de los ingre- sos fiscales obtenidos como resultado de esta actividad por los países receptores o de origen.

Tampoco hay mayor información estadística sobre los impuestos pagados o por pagar sobre las tenencias en cartera de títulos de participación en el capital y títulos de deuda. En general, la práctica utilizada en la región es no gravar los intereses, dividendos o ganancias de capital que perciben los no residentes, con el argumento de que el gravamen sólo aumentaría el costo de los préstamos por encima de la tasa de retorno vigente en los mercados de capital internacionales más la prima de riesgo país. Este criterio se basa en el precedente establecido por los Estados Unidos en 1984, de eximir del impuesto retenido en la fuente (withholding tax) a los extranjeros que no residen en el país y cuyas carteras de inversiones les devengan intereses (OCDE, 1998). Los no residentes que invierten en la bolsa de los Estados Unidos están exentos del pago de impuestos sobre las ganancias de capital, pero deben pagar el impuesto estadounidense sobre los di- 
videndos devengados. La decisión de los Estados Unidos obligó a todos los demás países industrializados a hacer lo propio.

Si bien los países industrializados pueden gravar las ganancias de capital obtenidas en el extranjero por sus propios residentes, muchos países en desarrollo no están en condiciones de hacerlo debido a su infraestructura tributaria. El Convenio de la OCDE y del Consejo de Europa sobre asistencia mutua en materia tributaria, firmado en 1988, garantiza que la información sobre estas tenencias se comparta con otros gobiernos de la OCDE, pero no con países que no son miembros de esa organización. Con respecto a las grandes tenencias internacionales en cartera de los residentes de América Latina y el Caribe, los datos son aún más escasos, pues la mayor parte de esos activos no han sido declarados a las autoridades tributarias de esos residentes. ${ }^{5}$ Sin embargo, el análisis de los datos del
Banco de Pagos Internacionales sobre los depósitos bancarios internacionales indica que los depositantes no bancarios son muy sensibles a los impuestos nacionales sobre el patrimonio, a la obligación de declarar los intereses devengados y a las tasas de interés. Esto significa que la evasión fiscal es uno de los factores que determinan tales depósitos y que la sensibilidad mencionada aumentó significativamente durante el decenio de 1990 (Huizinger, 2001).

En consecuencia, la investigación empírica se ha centrado en la tributación de los ingresos devengados por las filiales extranjeras, en especial de las empresas estadounidenses, ya que el Departamento de Comercio de los Estados Unidos publica datos extraordinariamente detallados. Podemos suponer que las cifras del cuadro 2 son representativas de los impuestos pagados por todas las filiales extranjeras en la región. La tasa tributaria efectiva media de América Latina y el

CUADRO 2

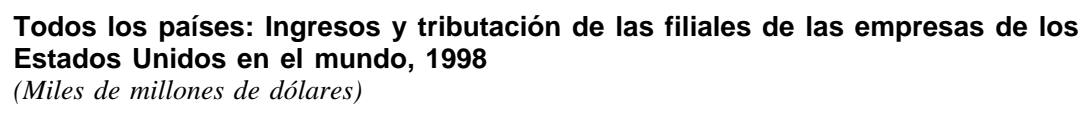

\begin{tabular}{|c|c|c|c|c|c|c|}
\hline & $\begin{array}{c}\text { Ingresos } \\
\text { declarados }\end{array}$ & $\begin{array}{l}\text { Costo de } \\
\text { las ventas }\end{array}$ & $\begin{array}{l}\text { Impuestos sobre } \\
\text { los ingresos pagados } \\
\text { en el extranjero }\end{array}$ & $\begin{array}{l}\text { Ingresos } \\
\text { netos }\end{array}$ & $\begin{array}{l}\text { Tasa efectiva del } \\
\text { impuesto sobre } \\
\text { los ingresos }(\%)\end{array}$ & $\begin{array}{l}\text { Otros impuestos } \\
\text { locales pagados }\end{array}$ \\
\hline Todos los países & 2115 & 1937 & 41 & 137 & 23 & 112 \\
\hline Canadá & 248 & 233 & 5 & 10 & 33 & 7 \\
\hline Europa & 1208 & 1102 & 22 & 84 & 21 & 73 \\
\hline América Latina y el Caribe & 245 & 218 & 5 & 23 & 17 & 14 \\
\hline Africa & 22 & 19 & 1 & 2 & 38 & 1 \\
\hline Oriente Medio & 10 & 8 & 1 & 1 & 50 & 14 \\
\hline Asia y el Pacífico & 378 & 358 & 8 & 17 & 32 & 3 \\
\hline América del Sur & 127.0 & 120.7 & 1.8 & 4.5 & 25 & 11.7 \\
\hline Centroamérica & 77.0 & 69.5 & 1.9 & 5.7 & 25 & 2.3 \\
\hline Caribe & 41.3 & 27.7 & 1.0 & 12.5 & 7 & 0.4 \\
\hline Argentina & 21.4 & 20.5 & 0.4 & 0.4 & 50 & 2.6 \\
\hline Brasil & 67.0 & 63.2 & 0.6 & 3.2 & 16 & 7.2 \\
\hline Chile & 10.1 & 9.1 & 0.2 & 0.8 & 20 & 0.5 \\
\hline México & 67.5 & 61.6 & 1.7 & 4.1 & 29 & 1.8 \\
\hline Venezuela & 10.3 & 10.2 & 0.2 & $\ldots$ & $\ldots$ & 0.5 \\
\hline $\begin{array}{l}\text { Bermuda } \\
\text { Indias Occidentales }\end{array}$ & 18.0 & 11.3 & 0.3 & 6.5 & 4 & $\ldots$ \\
\hline Británicas & 11.7 & 7.6 & 0.2 & 3.9 & 3 & $\ldots$ \\
\hline
\end{tabular}

Fuente: Cifras calculadas por el autor, sobre la base de los datos obtenidos en el Departamento de Comercio de los Estados Unidos. La "tasa efectiva del impuesto sobre los ingresos" es el impuesto sobre los ingresos pagado en el extranjero, dividido por los ingresos brutos (ingresos netos más el impuesto sobre los ingresos pagado en el extranjero).

\footnotetext{
${ }^{5}$ Las estadísticas detalladas que publica el Departamento del Tesoro de los Estados Unidos sobre las tenencias extranjeras de activos financieros estadounidenses (principalmente depósitos bancarios y bonos del gobierno) no permiten determinar las tenencias de los residentes en América Latina y el Caribe. En primer lugar, porque
}

incluyen los resultados de las operaciones de los bancos de la región, con inclusión de las reservas de los bancos centrales; y en segundo lugar, porque las tenencias más importantes provienen de los centros financieros extraterritoriales y por lo tanto pertenecen a no residentes en esos centros. 
Caribe está bien por debajo de la que se paga en cualquier otra región del mundo. Sin embargo, esto se debe casi exclusivamente a la incidencia de los países de "fiscalidad baja" del Caribe: según la información disponible, dos jurisdicciones caribeñas por sí solas (Bermuda y las Indias Occidentales Británicas) tienen mayores ingresos brutos que las cinco economías más importantes del continente, mientras que sus tasas tributarias efectivas son la décima parte de las de cualquier otro país de la región. Por el contrario, las tasas efectivas de América del Sur y Centroamérica son similares a las de Europa, aunque menores que las de Asia.

Además, como muestra el cuadro 3 , la situación actual obedece a una tendencia general decreciente de la carga tributaria en las principales economías de la región; el promedio para Argentina, Brasil, México y Venezuela disminuyó de 50\% en el período 1983-1986 a $25 \%$ en el período 1993-1997. Esto es sin duda consecuencia de una competencia tributaria cuyo objeto es atraer la inversión extranjera.

Conover y Nichols (2000) confirman conclusiones anteriores en el sentido de que las empresas estadounidenses de hecho "trasladan" ingresos por todo el mundo en gran escala, aunque sí respondieron a la Ley de Reforma Tributaria de 1986, remitiendo las utilidades a los Estados Unidos. Lo mismo puede decirse de las empresas de los países europeos miembros de la OCDE, en las que se realiza una amplia reestructuración de los precios de transferencia y del capital (por ejemplo, las deudas intrafirma), inducida por la tributación, pese a que la Convención modelo sobre el ingreso y el capital y las Directrices sobre precios de transferencia de la OCDE preconizan la aplicación de precios de mercado a las transacciones intrafirma (Bartelsman y
Beetsma, 2000). El análisis de los datos de los Estados Unidos realizado por Altshuler, Gruber y Newlon (1998) confirma este punto de vista, indicando que la elasticidad de las inversiones manufactureras estadounidenses en el exterior con respecto a las tasas impositivas del país receptor es mayor que la unidad y creció entre los decenios de 1980 y $1990 .^{6}$

Como se ha visto, los países desarrollados tienden a aplicar el principio de la tributación según la residencia, pues habitualmente la posición neta de los activos en el exterior es positiva y este principio permite maximizar los beneficios tributarios. Por lo general, los países en desarrollo prefieren el principio de la tributación según la fuente, porque son receptores de cuantiosos volúmenes de IED. Sin embargo, varios mercados emergentes, como Argentina y México, han modificado el régimen impositivo, cambiando la tributación según la fuente por la tributación según la residencia, con el objeto de estimular las inversiones extranjeras y captar los ingresos procedentes de los activos externos de sus residentes.

El problema para los países en desarrollo se ve agravado por el hecho de que los principales países industrializados aplican sistemas internacionales de impuestos sobre los ingresos que se apartan de ambos principios en su forma más pura. Por ejemplo, los Estados Unidos gravan tanto los ingresos devengados en el exterior por los residentes estadounidenses como

\footnotetext{
${ }^{6}$ Concretamente, los autores estiman que la elasticidad aumentó de -2 a +3 entre 1984 y 1992. Curiosamente, esta cifra es muy similar al valor de la elasticidad correspondiente $(-1 / 1-\beta)$ entre el acervo de capital $K$ y la tasa impositiva $t$ pronosticado por el modelo expuesto en el apéndice para valores plausibles de los parámetros.
}

América Latina y el Caribe: Ingresos y tributación de las filiales de empresas de los Estados Unidos en la región, 1998

(Miles de millones de dólares)

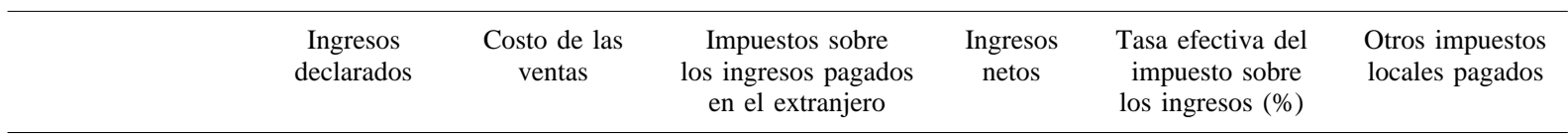

Total de América

Latina y el Caribe

América del Sur

Centroamérica

Caribe

$\begin{array}{rr}245.1 & 217.8 \\ & \\ 127.0 & 120.7 \\ 77.0 & 69.5 \\ 41.3 & 27.7\end{array}$

Fuente: Cifras calculadas por el autor, sobre la base de los datos obtenidos en el Departamento de Comercio de los Estados Unidos. La "tasa efectiva del impuesto sobre los ingresos" es el impuesto sobre los ingresos pagado en el extranjero, dividido por los ingresos brutos (ingresos netos más el impuesto sobre los ingresos pagado en el extranjero). 
los ingresos obtenidos en los Estados Unidos por los no residentes en ese país. Además, generalmente no reconocen la totalidad de los impuestos pagados en el exterior como parte de las obligaciones tributarias en los Estados Unidos. Este sistema integral tiende a desalentar las inversiones en el exterior, porque se aparta del principio de "neutralidad en la exportación de capitales", es decir, la tasa impositiva varía según el país de destino. Por otra parte, actualmente los Estados Unidos aplican distintas reglas a la tributación sobre ingresos externos devengados por residentes en aquel país, según que las operaciones sean realizadas directamente por personas estadounidenses (por ejemplo, a través de una filial en el exterior) o indirectamente, a través de una empresa extranjera.

En la actualidad, los ingresos obtenidos fuera de los Estados Unidos en el primer caso están sujetos a impuestos, mientras que en el segundo sólo se gravan los ingresos al distribuirse a personas estadounidenses. De manera que, si los inversionistas de los Estados Unidos recurren a la modalidad empresarial para sus operaciones en el exterior, pueden diferir las imposiciones en el país y aprovechar los diferenciales tributarios entre países, al menos en el corto plazo. Además, a fin de regular los créditos fiscales externos disponibles y otros asuntos afines (como la postergación de la tributación en los Estados Unidos de los ingresos obtenidos en el exterior), el sistema se ha convertido en un conjunto sumamente complejo de reglas que desalienta la movilidad de los capitales y alienta el uso de los paraísos fiscales para realizar las inversiones externas.

El estudio publicado por la OCDE (2001) es el más fundamentado de los trabajos recientes sobre el problema de los incentivos tributarios a la IED, tanto en lo que se refiere a los países miembros de esta organización como a los que no son miembros de ella. En él se muestra que el impuesto sobre los ingresos de las empresas constituye un apoyo importante para la aplicación de los impuestos sobre las ganancias de capital de los accionistas. También cumple una función de retención para las empresas extranjeras. Asimismo, se justifica como un cobro por los bienes y servicios públicos, y por el aporte de los gobiernos locales en la renta económica. La OCDE recomienda cautela acerca del uso de incentivos para promover la IED —especialmente medidas como las moratorias impositivas, que promueven la elusión fiscal-y subraya los riesgos que entraña otorgar beneficios excesivos al acervo de capital existente en contraposición con las nuevas inversiones netas. Buena parte de los efectos de reasignación deseados puede lograrse mediante un nuevo diseño de la estructura tributaria en lugar de recurrir a reducciones generalizadas.

Las empresas que más probablemente modifiquen sus decisiones de localización en función de los niveles de tributación serán aquellas empresas transnacionales cuya meta es minimizar los costos en el corto plazo y que tienden a hacer hincapié en una producción de bajo valor agregado. Las empresas transnacionales cuyo objetivo es maximizar la rentabilidad en el largo plazo están más interesadas en asegurar la flexibilidad de sus estructuras internacionales de producción y, por ende, en otros factores vinculados con la localización, como la calidad de la mano de obra, la estabilidad de la moneda, el acceso a los mercados y la disponibilidad de recursos naturales. Consideran que las desgravaciones impositivas son beneficios imprevistos que se tienen en cuenta (y se reclaman) sólo después de que se hayan cumplido otros criterios más importantes. Además, si bien los incentivos fiscales pueden justificarse por el deseo de generar externalidades tecnológicas, en la práctica la capacidad de una economía en desarrollo para aprovechar estos beneficios depende de la existencia previa de una capacidad empresarial adecuada y de una fuerza de trabajo capacitada y, por lo tanto, de la existencia de impuestos relativamente elevados (Blomström, 2001).

Otro problema asociado con este tema es el de los centros financieros extraterritoriales. Al permitir que las empresas transnacionales, a través de los precios de transferencia, declaren la mayor parte de sus ganancias en sociedades ficticias radicadas en estos centros, los ingresos tributarios resultantes de la inversión y producción en países en desarrollo que no sean centros extraterritoriales se pierden para los países receptores. ${ }^{7}$ El Foro sobre Estabilidad Financiera (2000) abordó el tema de los centros extraterritoriales desde el punto de vista de la inestabilidad sistémica de los mercados internacionales de capitales. Los centros que no pueden o no quieren adherir a las normas internacionales de supervisión (en razón de la debilidad de sus prácticas de supervisión o de la falta de cooperación o de transparencia) plantean problemas en materia prudencial para la supervisión eficaz de los intermediarios financieros internacionales y problemas de integridad del mercado vinculados con la eficacia de las actividades

\footnotetext{
${ }^{7}$ Un caso especialmente conflictivo es el uso de empresas extranjeras de ventas para reducir la carga impositiva de los exportadores estadounidenses, pero como esto se hace principalmente a través de las Islas Vírgenes de los Estados Unidos, el tema escapa al alcance de este documento.
} 
internacionales de fiscalización de las actividades ilícitas y de las conductas de mercado indebidas.

El Grupo de Acción Financiera sobre el Lavado de Dinero (OCDE, 2000) definió, en un principio, 35 jurisdicciones como "países o territorios que no cooperan" en áreas clave de la transparencia y el intercambio de información necesarias para cumplir con las normas internacionales contra el lavado de dinero. La lista incluía a las Bahamas, Dominica, las Islas Caimán, Panamá, Saint Kitts y Nevis y San Vicente y las Granadinas, en la región, y también Filipinas, Israel, Líbano, Liechtenstein y Rusia. Seis de estos países y territorios, con inclusión de Bermuda y las Islas Caimán, se comprometieron rápidamente a eliminar las prácticas indebidas para fines de 2005. Tras la adopción de medidas globales contra el terrorismo después de septiembre de 2001, los demás Estados del Caribe y territorios británicos ${ }^{8}$ en la región habían comprometido, para febrero de 2002, su adhesión a normas internacionales de transparencia, intercambio de información y competencia leal en materia tributaria.
Por último, en los últimos años, las inversiones de cartera extranjeras han sido objeto de varias medidas tributarias encaminadas al control de los ingresos y egresos de capitales en varios mercados emergentes. Aunque en el presente documento se aborda la tributación directa sobre los ingresos procedentes de activos extranjeros y no los impuestos indirectos (es decir, sobre el volumen de negocios) que afectan a las transacciones de activos, ${ }^{9}$ cabe observar que los impuestos retenidos en la fuente sobre los ingresos de los activos pueden tener un efecto moderador similar, ya que si bien la base es menor la tasa es mucho más elevada (Zee, 2000). Evidentemente, este tipo de impuesto puede diseñarse de modo tal que incentive a los inversionistas extranjeros a adquirir activos con plazos de vencimiento mayores o a mantenerlos durante más tiempo. Además, este tipo de impuesto retenido en la fuente se aplicaría a muchos residentes tenedores de títulos nacionales (especialmente bonos del gobierno de alto rendimiento) adquiridos mediante mecanismos extraterritoriales a fin de evitar la tributación.

\section{V}

\section{Nuevas cuestiones de política para América Latina y el Caribe}

Desde el punto de vista de las autoridades tributarias de los países en desarrollo, actualmente los acuerdos de doble tributación son la única manera confiable de controlar las transacciones intrafirma y de esta manera resolver el problema de los precios de transferencia (OCDE, 1998). Así, es necesario asegurar la posibilidad de lograr un intercambio de información mucho más amplio que el actual, en el marco de los tratados existentes, especialmente en lo que se refiere a los activos radicados en los Estados Unidos. Sin embargo, estas medidas resultan ineficaces si se emplean los centros extraterritoriales como puntos de fijación de precios de transferencia y de elusión tributaria. En consecuencia, ante la inexistencia de un acuerdo tributario multilateral integral, sería deseable una revisión de los créditos fiscales establecidos en los actuales acuerdos de doble tributación. Lo mismo puede decirse de la aplicación

${ }^{8}$ También las Islas del Canal (o Anglonormandas). del principio de "traslado" a los paraísos fiscales empleado por los Estados Unidos.

Si se aplicaran de manera uniforme, tanto el principio de tributación según la fuente como el principio de tributación según la residencia, podrían servir de base para un sistema eficaz de cooperación tributaria internacional. Así, Tanzi (1996a, 1996b y 1998) sostiene que ha llegado el momento de crear algún tipo de organización tributaria mundial, cuya función no sería fijar o recaudar impuestos (lo que no resultaría políticamente viable) sino más bien brindar apoyo a las autoridades nacionales pertinentes. Esta organización: i) vigilaría los sistemas tributarios en todo el mundo; ii) constituiría un foro de políticas; iii) resolvería las controversias en materia de competencia tributaria; iv) ejercería una presión moral sobre quienes se bene-

\footnotetext{
${ }^{9}$ No obstante, véase un análisis exhaustivo de este tema en FitzGerald (1999).
} 
fician sin asumir carga alguna; v) recopilaría estadísticas tributarias; vi) transmitiría las mejores prácticas, y vii) elaboraría códigos de conducta para la administración tributaria.

Sin embargo, resulta difícil imaginar cómo se podría implementar esta propuesta. No es probable que los Estados Unidos estén dispuestos a modificar su propio sistema tributario con el solo objeto de aumentar la participación de otros países en la recaudación tributaria. Las posibilidades de reforma son algo mejores en la Unión Europea, debido a los esfuerzos que se están haciendo para armonizar las normas tributarias de las empresas en el mercado único y el acuerdo incipiente sobre la prevención de la competencia y la evasión tributarias entre Estados miembros. El interés de los miembros de la OCDE en coordinar medidas contra la elusión y la evasión de impuestos y la competencia entre ellos — con la consiguiente presión sobre los centros extraterritoriales- es indicativo de su preocupación por sus propias bases imponibles. Ampliar estas medidas de cooperación a los países de ingresos medios que no son miembros de la OCDE (muchos de los cuales ya son reconocidos como observadores en la organización) sería un paso lógico y técnicamente viable.

El solo hecho de que las autoridades tributarias de los países industrializados proporcionaran información mejoraría la situación. Como los datos se recopilan de todos modos, con el objeto de gravar los dividendos, el costo final no sería abrumador. Esta alternativa exigiría tener confianza en la capacidad administrativa, la independencia y la reserva de las autoridades tributarias de al menos los países más importantes de América Latina. Durante un período de transición, una alternativa posible sería recaudar los impuestos en la fuente y simplemente transferirlos a las autoridades del país de residencia. Como mínimo, podrían establecerse los principios de intercambio de información en el marco de la proyectada Area de libre comercio de las Américas, como contrapartida de los derechos de propiedad garantizados con arreglo a las disposiciones propuestas en materia de inversiones.

La propuesta de la Unión Europea de gravar los pagos de intereses transfronterizos - la directiva sobre el impuesto retenido en la fuente- demuestra que una medida de este tipo es viable (Comisión Europea, 1998). Aun quienes se oponen a ella coinciden en que en principio los impuestos retenidos en la fuente se justifican porque tienen un efecto neutro para los inversionistas que declaran debidamente sus obligaciones tributarias en otro sitio, pero a menos que se apli- que en forma universal lo único que se lograría es trasladar el lugar formal en que se realizan los pagos de los tributos. Los avances logrados en la propuesta europea, aunque limitados al intercambio de información sobre los pagos, podrían constituir un precedente para los países de América Latina y el Caribe. En este contexto, Zee (2000) defiende un impuesto retenido en la fuente sobre todas las entradas de capital a los mercados emergentes, que incluya una disposición de crédito y reintegro que opere en el marco administrativo del sistema tributario existente del país receptor y que sería mucho más difícil de evadir que las reservas obligatorias.

Como se ha señalado, los esfuerzos por mejorar la coordinación entre las autoridades tributarias nacionales con el objeto de abordar el tema del delito organizado y el blanqueo de dinero, pueden servir para reformar la administración tributaria. Tanto los bancos como los reguladores han sido objeto de fuertes presiones para compartir información sobre las transacciones financieras, como parte de estas medidas de lucha contra el delito, y en ese proceso, divulgar información sobre los activos en el exterior de los residentes de una jurisdicción tributaria determinada. Esto podría apuntar a la necesidad de lograr en la región un mayor intercambio de conocimientos técnicos y de información propiamente dicha.

La existencia de un acuerdo regional de cooperación en materia tributaria (como el de la Unión Europea) permite mejorar la coordinación dentro de la región, posibilitando un aumento de la recaudación y de la entrada de inversiones, sin que haya coordinación global (Haufler y Wooton, 2001). De hecho, a medida que los incentivos a las inversiones en los países en vías de industrialización han evolucionado en los últimos años hacia el "campo regulatorio" en lo que se refiere al acceso a los mercados, a la protección del medio ambiente y a las normas laborales, también se ha hecho necesaria una mayor cooperación a fin de evitar una "carrera hacia el abismo" (FitzGerald, 2001). Además, un acuerdo regional que haga más predecibles las normas tributarias nacionales tendrá un efecto positivo, porque la incertidumbre sobre la rentabilidad futura puede tener un impacto desproporcionado sobre las decisiones de inversión (Dixit y Pindyck, 1994).

Así pues, el intercambio de información es esencial para la cooperación en materia tributaria, aunque es preciso recordar que la amplitud y utilidad de estos intercambios se ven limitadas por obstáculos políticos, jurídicos, técnicos y administrativos (Tanzi y Zee, 1999). En general, los impuestos retenidos en la fuente pueden ser la única solución al problema de los 
ingresos fiscales. Es poco probable que pueda desarrollarse un sistema eficiente y completo de intercambio de información. Este hecho deja abierta la posibilidad de utilizar la recaudación de los impuestos retenidos en la fuente en el lugar donde se originan, como impuestos finales (Tanzi, 1998, pág. 21). Concretamente, para abordar el problema de la transferencia de ingresos, se podría aplicar a las empresas un impuesto presunto sobre la base de sus activos brutos en lugar de sobre los beneficios declarados.

En resumen, las presiones en favor de una cooperación internacional eficaz para facilitar la recaudación de los impuestos sobre los ingresos están aumentando. La creciente movilidad de los capitales a través de las fronteras nacionales plantea graves problemas a las autoridades tributarias de los países, preocupadas por gravar la renta derivada de la riqueza. La cooperación entre las autoridades tributarias podría atenuar algunos de estos problemas, pero los conflictos jurisdiccionales y las leyes de secreto bancario han obstaculizado los avances en este sentido. Sin embargo, los progre- sos alcanzados en materia de cooperación tributaria entre los países miembros de la OCDE — sobre todo los miembros de la Unión Europea- no sólo sientan un precedente para un acuerdo regional, sino que constituyen la base para exigir la cooperación de los países desarrollados. En los países de América Latina y el Caribe, dicho acuerdo también permitiría captar una proporción mucho mayor de los ingresos tributarios correspondientes a los ingresos del capital de sus propios residentes, no sólo de los activos no declarados en el extranjero sino también de los activos existentes en el país, reduciendo el interés por expatriar los capitales o la propiedad. Una colaboración más estrecha, en el marco de la red existente de tratados tributarios, mediante el intercambio de información y la adopción de medidas conjuntas, permitiría aumentar los recursos fiscales disponibles en la región. Esto traería aparejados otros beneficios, como los desincentivos a la fuga de capitales, una mayor estabilidad fiscal y macroeconómica y un aumento de los recursos disponibles para reducir la pobreza.

APENDICE

\section{Un modelo simple de impuesto sobre los ingresos del capital en una economía abierta}

Esta nota tiene por objeto ilustrar el problema de la tributación óptima sobre los ingresos del capital en una economía con un mercado de capital abierto y dos tipos de capitales: uno de ellos privado, móvil y "directamente productivo" (es decir, que genera ingresos) y el otro público, inmóvil e "indirectamente productivo" (es decir, infraestructura). El problema consiste en establecer un nivel de tributación que permita financiar la infraestructura y maximizar el bienestar cuando el capital puede emigrar al exterior.

Considérese una economía en la que intervienen tres factores de producción: la mano de obra inmóvil $L$, el capital móvil $K$ y la infraestructura financiada mediante los impuestos $J$. El ingreso nacional $Y$ está determinado por

$$
Y=A \cdot L^{\alpha} K^{\beta} J^{\gamma}
$$

En condiciones normales, el retorno del capital $r$ puede determinarse mediante la expresión siguiente:

$$
r=\frac{\partial Y}{\partial K}=\beta \cdot L^{\alpha} K^{\beta-1} J^{\gamma}
$$

La fuerza de trabajo y el acervo de infraestructura se consideran para un período determinado, pero el acervo de capital es flexible, ya que puede entrar y salir, según cuál sea la tasa de retorno después de deducir los impuestos. También se podría incluir una prima de riesgo adecuada, pero si es constante no afectará los resultados. Considerando la tasa tributaria de un país determinado $t$ y las tasas tributarias internacionales exógenas $t^{*}$ y de retorno $r^{*}$, el capital ingresará al país siempre y cuando las tasas de retorno después de deducir los impuestos resulten atractivas: es decir, si $r(1-t) \geq r^{*}\left(1-t^{*}\right)$. En este análisis se hace caso omiso del efecto de los acuerdos de doble tributación, que producen una disminución efectiva de $t$, no sólo en el país receptor sino también en los países con los cuales aquél tiene acuerdos similares. En consecuencia, en el equilibrio

$$
r(1-t)=r^{*}\left(1-t^{*}\right)
$$

y sustituyendo la ecuación [3] en la [2] se obtiene el acervo de capital de equilibrio

$$
K=\left\{\frac{\beta \cdot L^{\alpha} J^{\gamma}(1-t)}{r^{*}\left(1-t^{*}\right)}\right\}^{\frac{1}{1-\beta}}
$$

Obsérvese que esto dotará al acervo de capital de una elasticidad con respecto a la tasa tributaria que será negativa y mayor que la unidad. Así, si se sustituye la ecuación [4] en la [1], se obtiene el ingreso nacional $Y$ en función de dos tasas tributarias:

$$
Y=\left[A L^{\alpha} J^{\gamma}\left\{\frac{\beta(1-t)}{r^{*}\left(1-t^{*}\right)}\right\}^{\beta}\right]^{\frac{1}{1-\beta}}
$$

De la ecuación [5] parece deducirse que ante cualquier incremento de la tasa tributaria nacional a las empresas $t$ se producirá una disminución del ingreso nacional $Y$. La tasa óptima es cero, o incluso negativa (subsidios), a condición de que éstos puedan financiarse. Esta constituye la base del argumento tradicional en favor de reducir las tasas tributarias a las empresas en los países en desarrollo con el fin de estimular la inversión y el crecimiento. Además, 
parece evidente que si la tasa tributaria internacional $t^{*}$ en general - o la de los países que compiten por obtener inversiones del exterior en particular - disminuye, para mantener los niveles de ingreso nacional también será necesario reducir $t$. De este modo, se considera que la competencia tributaria internacional favorece la maximización del bienestar.

Sin embargo, para que se cumpla esta condición es preciso suponer que tanto la fuerza de trabajo $L$ como la infraestructura disponible $J$ es independiente de la tasa tributaria. En este modelo, el acervo de infraestructura $J$ es el acervo del año anterior, menos la depreciación $d$ más las nuevas inversiones financiadas con los ingresos provenientes de los impuestos sobre las utilidades K.r

$$
J=J_{-1}(1-d)+t . K . r
$$

A fin de simplificar la expresión algebraica, sólo se tomará en cuenta el término de la derecha de la ecuación [6], porque el primer término no varía con la tasa tributaria. Así se puede volver a escribir la ecuación [1], haciendo una sustitución con la ecuación [6] truncada y obtener

$$
Y=A \cdot L^{\alpha}\{t r\}^{\gamma} K^{\beta+\gamma}
$$

Sustituyendo en las ecuaciones [2] y [3] como antes, se obtiene una nueva expresión para el ingreso nacional

$$
Y=\left[a \cdot L^{\alpha} \cdot \beta^{\beta}\left\{r^{*}\left(1-t^{*}\right)\right\}^{-\beta} t^{\gamma}(1-t)^{\beta}\right]^{\frac{1}{1-\beta-\gamma}}
$$

$Y$ ya no está relacionada en forma monotónica e inversa con $t$ en la ecuación [8], como ocurría en la ecuación [5], porque un aumento tributario ya no genera una disminución del acervo de capital privado $K$ sino que también incrementa el acervo público $J$. En las condiciones habituales, existe un valor óptimo y positivo de $T$ para el cual el ingreso $Y$ se maximiza, calculando la derivada de $Y$ con respecto a $t$ en la ecuación [7]

$$
T=\frac{\gamma}{\beta+\gamma}
$$

Así, la tasa tributaria óptima es positiva y depende de las productividades marginales relativas de las dos formas de acervo de capital $K, J$. De hecho, si la tasa tributaria se fija en cero, el ingreso nacional también será cero y no habrá infraestructura. Por extensión, en los países pobres, donde la infraestructura $J$ es escasa y la productividad marginal es más elevada (mientras que la productividad marginal del capital móvil $K$ es la misma en todo el mundo), las tasas impositivas de las empresas deberían ser más elevadas que en los países avanzados.

De la ecuación [8] queda claro también que el nivel resultante de ingreso nacional seguirá dependiendo de la tasa tributaria internacional $r^{*}$, incluso tras la aplicación de la tasa tributaria nacional óptima. Si los países de origen (es decir, aquéllos de donde provienen las inversiones) o los países receptores competidores reducen la tasa internacional, caerá el ingreso nacional del país receptor, pues se atraerá menos capital móvil. Sin embargo, aun en ese caso (reducción de $t^{*}$ ), iniciar una "carrera hacia el abismo" (es decir, fijar el valor de $t$ por debajo del de $T$ ) reducirá el ingreso nacional del país receptor aun más.

(Traducido del inglés)
Andersson, F. y R. Forslid (1999): Tax Competition and Economic Geography, CEPR discussion paper, $\mathrm{N}^{\circ} 2220$, Londres, Centro de Investigación sobre Políticas Económicas.

Altshuler, R., H. Gruber y T. Newlon (1998): Has US Investment Abroad Become More Sensitive to Tax Rates?, NBER working paper, $\mathrm{N}^{\circ} 6383$, Cambridge, Massachusetts, Oficina Nacional de Investigaciones Económicas.

Baldwin, R. y P. Krugman (2000): Agglomeration, Integration and Tax Harmonisation, CEPR discussion paper, $\mathrm{N}^{\circ} 2630$, Londres, Centro de Investigación sobre Políticas Económicas.

Bartelsman, E. y R. Beetsma (2000): Why Pay More? Corporate Tax Avoidance through Transfer Pricing in OECD Countries, CEPR discussion paper, $\mathrm{N}^{\circ} 2543$, Londres, Centro de Investigación sobre Políticas Económicas.

Blomström, M. (2001): The Economics of International Investment Incentives, París, Organización de Cooperación y Desarrollo Económicos (OCDE).

Bovenberg, A. (1994): Capital taxation in the world economy, en F. Van der Ploeg, The Handbook of International Macroeconomics, Oxford, Reino Unido, Blackwell.

Comisión Europea (1998): Proposal for a Council Directive to ensure a minimum of effective taxation of savings income in the form of interest payments within the Community, Bruselas.

Congreso de los Estados Unidos, JCT (Joint Committee on Taxation) (1999): Overview of Present-Law Rules and Economic Issues in International Taxation, Washington, D.C.

Conover, T. y N. Nichols (2000): A further examination of income shifting through transfer pricing considering firm size and/or distress, International Journal of Accounting, vol. 35, $\mathrm{N}^{\circ} 2$.

Diamond, P. y J. Mirrlees (1971): Optimal taxation and public production, American Economic Review, vol. 61, N 1, Nashville, Tennessee, American Economic Association.
Dixit, A. (1985): Tax policies in open economies, en A. Auerbach y M. Feldstein (eds.) Handbook on Public Economics, Amsterdam, Países Bajos, North-Holland.

Dixit, A. y J. Pindyck (1994): Investment under Uncertainty, Princeton, New Jersey, Princeton University Press.

FitzGerald, E. V. (1999): Policy Issues in Market Based and Non Market Based Measures to Control the Volatility of Portfolio Investment, Development studies working papers, $\mathrm{N}^{\circ} 129$, Torino, Italia, Centro Studi Luca D'Agliano. (2001): Regulatory Investment Incentives, París, OCDE.

Foro sobre Estabilidad Financiera (2000): Report of the Working Group on Offshore Centres, Basilea.

Frenkel, J., A. Rain y E. Sadka (1991): International Taxation in an Integrated World, Cambridge, Massachusetts, MIT Press.

Giovannini, A. (1990): Reforming capital income taxation in open economy: Theoretical issues, en H. Siebert (ed.), Reforming Capital Income Taxation, Tübingen, Alemania, J.C.B. Mohr.

Gordon, R. (1986): The taxation of investment and savings in a world economy, American Economic Review, vol. 76, Nashville, Tennessee, American Economic Association.

Haufler, A. y I. Wooton (1999): Country size and tax competition for foreign direct investment, Journal of Public Economics, $\mathrm{N}^{\circ} 71$, Amsterdam, Países Bajos, Elsevier Science Publishers, B.V. (2001): Regional Tax Coordination and Foreign Direct Investment, CEPR discussion paper, $\mathrm{N}^{\circ} 3063$, Londres, Centro de Investigación sobre Políticas Económicas.

Huizinger, H. (2001): Are International Deposits Tax Driven?, Economic papers, $\mathrm{N}^{\circ} 152$, Bruselas, Comisión Europea.

IBFD (International Bureau of Fiscal Documentation) (1998): Annual Report 1997-1998, Amsterdam, Países Bajos. 
Kind, H., K. Knarvik y G. Schjelderup (1999): Competing for Capital in a Lumpy World, CEPR discussion paper, $\mathrm{N}^{\circ} 2188$, Londres, Centro de Investigación sobre Políticas Económicas.

Naciones Unidas, Departamento de Asuntos Económicos y Sociales (2001): United Nations Model Double Taxation Convention between Developed and Developing Countries, Nueva York.

Nielsen, S. y P. Sorensen (1991): Capital income taxation in a growing open economy, European Economic Review, vol. 34, Amsterdam, Países Bajos, Elsevier Science Publishers, B.V.

OCDE (1997): Model Double Taxation Convention on Income and Capital, París.

(1998): Harmful Tax Competition: an Emerging Global Issue, París.

(2000): Towards Global Tax Cooperation: Progress in Identifying and Eliminating Harmful Tax Practices, París. (2001): Corporate Tax Incentives for Foreign Direct Investment, París.

Plasschaert, S. (ed.) (1994): Transnational Corporations: Transfer Pricing and Taxation, Londres, Routledge.

Razin, A. y E. Sadka (1994): International fiscal policy coordination and competition, en F. van der Ploeg, The Handbook of International Macroeconomics, Oxford, Reino Unido, Blackwell.

Sen, P. y S. Turnovsky (1990): Investment tax credit in an open economy, Journal of Public Economics, vol. 42, $\mathrm{N}^{\circ} 3$, Amsterdam, Países Bajos, Elsevier Science Publishers, B.V.

Slemrod, P. (1990): Optimal taxation and optimal tax systems, The Journal of Economic Perspectives, vol. 4, $\mathrm{N}^{\circ}$ 1, Nashville, Tennessee, American Economic Association.
Sorensen, P. (1990): Optimal capital taxation in a small capitalimporting country, en V. Tanzi (ed.), Public Finance, Trade and Development, Detroit, Michigan, Wayne State University Press.

Stern, N. y D. Newbery (eds.) (1985): Taxation in Developing Economies, Washington, D.C., Banco Mundial.

Tanzi, V. (1996a): Taxation in an Integrating World, Washington, D.C., Brookings.

(1996b): Globalization, Tax Competition and the Future

of Tax Systems, IMF working papers, $\mathrm{N}^{\circ} 141$, Washington,

D.C., Fondo Monetario Internacional (FMI).

(1998): International Dimensions of National Tax Policy, trabajo presentado al UN Expert Meeting on International Economic and Social Justice, Nueva York.

Tanzi, V. y H. Zee (1999): Taxation in a borderless world: The role of information exchange, en B. Wiman (ed.), International Studies in Taxation, La Haya, Kluwer Law International.

UNCTAD (Conferencia de las Naciones Unidas sobre Comercio y Desarrollo) (1995): Incentives and Foreign Direct Investment, Ginebra.

(2001): World Investment Report 2001. Promoting Linkages, Ginebra.

Zee, H. (1998): Taxation of financial capital in a globalized environment: The role of withholding taxes, National Tax Journal, vol. 51, $\mathrm{N}^{\circ}$ 3, Washington, D.C., National Tax Association.

(2000): Retarding Short-Term Capital Inflows through Withholding Tax, IMF working papers, $\mathrm{N}^{\circ} 40$, Washington, D.C., FMI. 